\title{
Curatorial consumption: Objects' circulation and transference in the vintage marketplace
}

DOI:

10.1016/j.jbusres.2020.03.029

\section{Document Version}

Accepted author manuscript

Link to publication record in Manchester Research Explorer

\section{Citation for published version (APA):}

Abdelrahman, O. K., Banister, E., \& Hampson, D. P. (2020). Curatorial consumption: Objects' circulation and transference in the vintage marketplace. Journal of Business Research, 114, 304-311.

https://doi.org/10.1016/j.jbusres.2020.03.029

\section{Published in:}

Journal of Business Research

\section{Citing this paper}

Please note that where the full-text provided on Manchester Research Explorer is the Author Accepted Manuscript or Proof version this may differ from the final Published version. If citing, it is advised that you check and use the publisher's definitive version.

\section{General rights}

Copyright and moral rights for the publications made accessible in the Research Explorer are retained by the authors and/or other copyright owners and it is a condition of accessing publications that users recognise and abide by the legal requirements associated with these rights.

\section{Takedown policy}

If you believe that this document breaches copyright please refer to the University of Manchester's Takedown Procedures [http://man.ac.uk/04Y6Bo] or contact uml.scholarlycommunications@manchester.ac.uk providing relevant details, so we can investigate your claim.

\section{OPEN ACCESS}


Curatorial Consumption: Objects' circulation and transference in the vintage marketplace

Abdelrahman, O.K, Banister, E. and Hampson, D.P (2020), "Curatorial Consumption: Objects' circulation and transference in the vintage marketplace". Journal of Business Research. https://doi.org/10.1016/j.jbusres.2020.03.029 


\title{
Curatorial Consumption: Objects' circulation and transference in the vintage marketplace
}

\begin{abstract}
The role of objects' histories in shaping consumers' relationships with them has received limited attention outside the family setting. This paper proposes a wider view of curation within consumer research, one which moves beyond possessions' mnemonic links and also incorporates the consuming and selling of old objects within the marketplace. Drawing on indepth object interviews with 28 vintage enthusiasts, we shed light on how material remnants of the past are preserved in contemporary consumer culture. We identify how old objects' circulation and their actual and imagined historical associations shape consumer-object relations and associated meanings. We contribute to existing knowledge regarding consumers' relationships with their possessions by developing a conceptualization of curatorial consumption. Curatorial consumption is a dynamic process, whereby facets of the past are acquired, interpreted, preserved and transmitted to others.
\end{abstract}

Keywords: Curatorial Consumption; Ownership; Object interviews; Material Culture; Preservation; Vintage 


\section{Curatorial Consumption: Objects' circulation and transference in the vintage marketplace}

\section{Introduction}

This paper addresses a paucity of consumer research acknowledging the role of objects' pasts in shaping consumers' relationships with their possessions. We offer a theorization of curatorial consumption in order to forge understanding of how curation operates in the marketplace. Specifically, we focus on the vintage marketplace context and explore how individuals' (both sellers' and consumers') perceptions of objects' pasts inform their relationships with them and other associated behaviors. Our understanding of curatorial consumption incorporates the interplay of persons' perceptions of the past and objects' actual or imagined historical associations in shaping the meanings of possessions. The consumption of old objects has been increasing in popularity (Mintel, 2019). Recent media and market reports estimate the second-hand market at over $\$ 20 \mathrm{bn}$ and project an increase of sales as the market continue to grow (Bramley, 2019; Mintel, 2019). The rise in sales is attributed to consumers' increasing environmental concerns and the resurgence of the fashion of past eras (Bramley, 2019; Mintel, 2019). Therefore, our study of consumers' relationship with their old items has the potential to offer theoretical and managerial insights.

Within the literature, there are various terms used to refer to old objects, such as 'heirlooms', 'second-hand', and 'vintage'. While this terminology has different symbolic connotations, understandings are linked by the way in which they associate old objects with past owners and eras (Curasi, Price, \& Arnould, 2004; Turunen \& Leipämaa-Leskinen, 2015). For the purpose of the study, we refer to 'old objects' as items that were previously owned or used, and are valued due to their past associations, such as with people, places, and eras (Pearce, 1993; Turunen \& Leipämaa-Leskinen, 2015). 
While the term curatorial consumption has been used in prior consumer research to describe the preservation of heirlooms and their meanings (McCracken, 1988a), it has not been developed beyond the family context (Curasi et al., 2004). This reflects a significant gap in understanding, given the role of the past in shaping person-object relations (Curasi et al., 2004; Türe \& Ger, 2016). Furthermore, the role that the circulation of objects plays in shaping personobject relations also remains understudied. This limits our understanding of consumers' relationships with their possessions, their consumption practices and their interactions with old objects in the marketplace. Prior work identifies how past associations inform the preservation of family heirlooms helping to maintain a sense of continuity with ancestors (Curasi et al., 2004; McCracken, 1988a). However, little research attention has been given to those old objects that may not be considered to have the mnemonic value associated with heirlooms. To address these gaps, we focus on the consumption and circulation of old objects in the marketplace, to explore how objects' actual and imagined historical associations to people, places and eras shape consumer-object relations.

This paper, therefore, enhances understandings of consumers' relationships with their possessions and how connections with the past are forged. Three research questions guide our focus: First, how does the circulation of old objects facilitate individuals' reflections of the past?; Second, how do individuals' perceptions of the past shape the meanings assigned to their possessions?; and third, how do objects' past associations influence the manner individuals interact with their possessions? To address these questions, we focus on the vintage marketplace and the community of enthusiasts who engage in selling and consuming old objects. Our two-year ethnography incorporated in-depth object interviews with vintage enthusiasts. We integrate insights from prior consumer research as well as disciplines such as anthropology and museum studies in order to highlight how objects' circulation across time and places influence how consumers perceive them (Appelgren \& Bohlin, 2015; Pearce, 1993) 
and how this serves to facilitate acts of curation. We adopt a material culture lens, whereby person-object relations are viewed as dialectical, allowing us to forge understanding of how each component shapes the other (Miller, 2010).

We make two key contributions to knowledge regarding consumers' relationships with their possessions and how consumers actively engage with the past through their consumption behavior. First, through our conceptualization of curatorial consumption, we suggest a wider view of curation in consumer research, that is to transcend objects' mnemonic links and the family context. This conceptualization focuses on old objects more generally (including those from the marketplace) and has the potential to enhance understandings of consumers' relationships with their possessions, in particular how they maintain a connection with the past and with others. Our perspective of curation, therefore, encompasses possessions with both mnemonic and familial associations (Curasi et al., 2004; McCracken, 1988a), as well as other old objects which maybe acquired due to their perceived historical associations. We suggest that this more developed understanding of the curatorial phenomenon with its relation to objects' historical and/or socio-cultural associations will help consumer researchers to develop a better understanding of the role of objects' pasts in shaping consumption and consumerobject relations.

Second, by centering our study on the circulation of old objects, we contribute to existing materiality literature (e.g. Bettany, Kerrane, \& Hogg, 2014; Ferreira \& Scaraboto, 2016), highlighting how objects' circulation and actual and/or imagined historical associations influence consumers' interactions with their possessions post-purchase. Moreover, this focus has the potential to contribute to current discussions around ownership in consumer behavior literature (e.g. Bardhi \& Eckhardt, 2017; Belk, 2014), highlighting how consumers may own, cherish and curate items, yet with being aware that their relations with objects are not always stable and enduring. 


\section{Literature Review}

\subsection{Curation of possessions}

Curatorial consumption was first introduced to the consumer research literature in a book chapter by McCracken (1988a). He drew on established practices of curation (e.g. the preservation and display of an item) to develop an account of the 'curatorial consumer' who exhibits a sense of responsibility towards family possessions and a desire to ensure their preservation through transferal to other family members. McCracken (1988a, p.49) described curatorial consumption as "a pattern of consumption in which an individual treats his or her possessions as having strong mnemonic value, and entertains a sense of responsibility to these possessions that enjoins their conservation, display, and safe transmission". To date, only a small number of researchers have engaged with the term. For example, Curasi et al. (2004) explore how consumers maintain kin relationships through family heirloom guardianship. This guardianship role involves ensuring heirlooms' preservation, through passing them, alongside the stories and meanings assigned to them, to new guardians (Curasi et al., 2004). For Curasi et al. (2004) and McCracken (1988a), curatorship emerges due to objects' familial and mnemonic associations and allows consumers to maintain a sense of continuity with their kin and the family past.

Recently, Abdelrahman, Banister, and Hampson (2019) expanded considerations of curatorial consumption beyond the family setting, identifying how vintage traders adopt roles as guardians for their merchandise. While the authors suggest the need to reconsider the existing interpretation of curatorial consumption, that is to go beyond objects' mnemonic associations (McCracken, 1988a), they fall short of offering an alternative conceptualization instead retaining a focus on preservation. In this paper, we build on this prior work to develop a theorization of curatorial consumption with potential application to a range of different consumption contexts. We extend the scope to incorporate objects' presumed historical 
associations, enhancing our understanding of both consumers' and sellers' relationships with old objects.

\subsection{Consumers and their possessions: A Material culture perspective}

A growing stream of literature recognizes the key role material elements (e.g. objects) play in shaping consumption practices and influencing consumers' experiences and identities (e.g. Bettany et al., 2014; Ferreira \& Scaraboto, 2016; Mullins, 2018). However, this literature tends to overlook objects' past from their discussions. Exceptions to this omission exist in research focused on family possessions. Türe and Ger (2016) identify how consumers modify their heirlooms in ways that reflect their tastes and identities, while maintaining a link with the family past and potentially acquiring new stories and memories, to pass on alongside objects in the future. Epp and Price (2010), use the example of a seemingly mundane object, a table, to identify how the item embodied memories and is key to how families construct their collective identity. They identify the importance of understanding complex networks, consisting of identity practices (e.g. family gatherings), spaces and other items, in order to understand the meanings and positions of such possessions (Epp \& Price, 2010). Yet, little is known about whether, and how, old objects lacking the mnemonic associations of family possessions might shape individuals' actions towards their possessions. To help us address this gap, we turn to Miller's (2010) dialectical theory of material culture.

Miller (2010) acknowledges the role of objects in shaping the social world, and in constituting consumers' identities and perceptions. Through interacting with objects, consumers come to understand themselves and others with identities and meanings becoming objectified or embedded into the objects (Miller, 2010). According to Miller (2010, p.94), "things do things to us, and not just the things we want them to do". Old objects, as a result of their longevity, can evoke past associations, and this may influence consumers' perceptions and actions (Belk \& Humayun, 2015; Miller, 2010; Pearce, 1993). For example, historic 
associations may influence how consumers decide to furnish their old houses (Miller, 2010) and re-incorporate old objects into a new home (Epp \& Price, 2010). However, extant research has not engaged fully with how old objects' circulation might play a role in shaping consumers' imagination of the past and their relationships with their possessions.

\subsection{Objects' circulation and transference}

In their seminal works, Kopytoff (1986) and Appadurai (1986) refer to objects' 'cultural biographies' and 'social lives' to highlight how the meanings and value assigned to objects change over time as a result of exchange processes and objects' interactions with people. An example would be when an object changes from being recognized as a commodity to being understood as a personal possession inscribed with meanings and memories. Conceiving old objects as having a previous life allows researchers to recognize the fluidity of this 'life'. Items can be purchased, become meaningful and then potentially be discarded. Sometimes these items circulate back into the marketplace to be recommodified, thus, re-starting this cycle (Kopytoff, 1986; Masset \& Decrop, 2016).

Researchers have started to perceive objects' circulation as more than the exchange of objects but rather having "a role in constituting objects and identities" (Aronczyk \& Craig, 2012, p.93). Kuruoğlu and Ger (2015) explore the interplay between emotions and the circulation of mundane objects such as cassettes. Their research within the Kurdish community notes that practices such as recording, listening to and circulating music cassettes, allow members to embody a shared heritage, thus solidifying connections and serving as a form of re-enforcing boundaries between 'us' and 'others'. The exchange of cassettes facilitated the transmission of communal experiences and emotions alongside a sense of belongingness among community members (Kuruoğlu \& Ger, 2015). Figueiredo and Scaraboto (2016) explore how the circulation of trackable-objects in collaborative consumer networks can inform both personal (e.g. hedonic) and collective (e.g. linking) value outcomes through the 
pursuit of geocaching. Arsel (2016, p.36) uses the example of a cosmetic item recirculating amongst a community, to highlight that "valuation is highly embedded into the social relations between people who participate, and a network of practices that circulate the goods from one marketplace actor to the other".

All old objects have histories that may pre-date their current ownership. Ownership involves person-object relations, where a consumer has full control over items, including the right to use and to sell or gift them to others (Belk, 2014). Transference specifically involves the circulation of an object from one person to another, such as when consumers pass on family possessions to intended heirs (Price et al., 2000). When objects are transferred to new recipients, this often also involves the transferal of the associated stories and memories (Price et al., 2000). This associated storytelling influences the meanings assigned to items. In the case of heirlooms, these stories may serve to sacralize them, making them inalienable (Curasi et al., 2004). Nevertheless, consumers" "engagement with the material world" also facilitates their imaginations, enabling them to construct their own interpretations and narratives (Chronis, Arnould, \& Hampton, 2012, p.281).

Throughout its circulation, an object accumulates "a history of its own, passing from one possessor to another, perhaps from one kind of use to another, and from one place to another" (Pearce, 1993, p.16). Such historical layers might physically materialize in the form of patina: signs of wear of time, which are interpreted and assigned meanings (McCracken,1988a). Consumers' imagination of objects' circulation across different temporal-spatial contexts might influence the manner in which they perceive the objects (Appelgren \& Bohlin, 2015), for instance, objects may be seen to embody a 'golden age' or be viewed as a valuable remnant from a bygone time. Mead $(1959$, p.12) describes the past as being "as hypothetical as the future", inferring its openness to interpretation and imagination. Such interpretations, for example, might be shaped by nostalgia which romanticizes the past, and the meanings of old 
objects (Goulding, 2002). These associated meanings may inform consumers' acquisition of objects, and particularly individuals' desire to ensure their preservation through passing them on to future users. We now turn to the context of our study.

\section{Context and Methods}

We focus on the UK vintage market context, wherein communities develop around the selling and consuming of old items. Although the term vintage is associated with the past and the age of an item, there is no consensus regarding when an item assumes the position of 'vintage'. For example, McColl et al.(2013, p.148) refer to vintage items as those that have been produced "more than twenty years ago, which represent a particular fashion era". Turunen and Leipämaa-Leskinen (2015, p.59) perceive vintage as "previously owned, but not necessarily used goods from a specific era". While it is clear that the value of 'vintage' items is associated with their past, no prior consumer research directly explores the way in which the objects' past and their historical associations influence consumers' relationships with their possessions. We focus on vintage markets as a context within which to explore how old objects' circulation helps shape the meanings associated with possessions, and how these, in turn, might shape person-object relations.

We employed participant observation at three vintage emporiums and fairs in northern England over a two-year period, in order to develop an in-depth understanding of the context and the different groups within it (i.e. traders/consumers). During this period of observation, participants for in-depth interviews were also recruited. We conducted 28 in-depth interviews with vintage enthusiasts including traders and consumers (Table 1). The interview lengths ranged from 42 minutes to approximately 4 hours.

[Table 1 here]

Interviews began with grand-tour questions focusing on participants' experiences within the vintage marketplace (McCracken, 1988b), then moved to resemble 'object interviews', 
whereby conversations were centered around specific material possessions (Woodward, 2019). Object interviews, sometimes referred to as 'object-elicitation', is an interviewing technique whereby interviewees' relationships with their possessions, and the meanings inscribed to those objects, are explored more directly (Woodward, 2019). Prior to the interview, our participants were asked to choose items that they had acquired from the marketplace and regarded as personally meaningful or interesting. During the interview, we asked participants to introduce their possessions and to talk about them in detail (e.g. how they acquired them, what the object meant to them), and further questions emerged based on their replies. Participants often recalled other objects, some of which were no longer in their possession, and incorporated them into their discussions. Putting objects at the foreground of the interview enabled us to develop a better understanding of participants' experiences and their relationship with their possessions and with others (Woodward, 2019).

A hermeneutic approach was used for data interpretation, where we moved between parts of the data and the whole to develop an interpretation (Thompson, 1997). The coding process involved considering the language used by participants (emic), that hints to aspects that are relevant from an academic (etic) perspective (Belk et al., 2013). The data were categorized, whereby particular excerpts were considered to relate to a certain phenomenon (Spiggle, 1994). This was followed by identifying patterns, comparing them across interviews to identify common themes and comparing those to prior understandings within the literature; we then used the themes to develop a conceptualization of curatorial consumption (Belk et al., 2013; Spiggle, 1994).

\section{Findings}

We present our conceptualization of curatorial consumption and its circular components (Figure 1). This conceptualization emerged from the data; yet is presented here in order to 
structure our findings which are developed around the following themes: object histories, curatorial practices, future imaginations, and transference.

[Figure 1 here]

First, we illustrate how participants' perceptions of their objects' actual or imagined historical associations shape the meanings they assign to their possessions. Second, we explore how participants act upon these meanings by engaging in curatorial practices. Finally, we note how they reflect on their actions and on their possessions' futures, thereby examining strategies of transference whereby possessions are passed to new recipients. We, therefore, conceptualize curatorial consumption as a dynamic process, whereby facets of the past are acquired, interpreted, preserved and transmitted to others.

\subsection{Object histories}

It became immediately clear that participants assigned their possessions with historical value. While this was often rooted in elements of 'history', this was also frequently blended with imagination. This is illustrated by Heidi:

"I was working with one of the footballs that was kicked across enemy line [s] at the Battle of the Somme [...] and [soldiers] kicked it to each other, to kind of boost each other's morale, to encourage them to approach the enemy line. Those footballs survived, but the men didn't [...]. I was thinking, it's such a tatty object, if you found it and didn't know....you'd just think, I'm going to put that in the bin [...] but... when [...] the object and the story are linked up, you then realise the importance of this [object] [...]. So, that's a very extreme example, but [..] I think that filters down into why we buy second-hand stuff, because you envisage all these fancy things, you imagine this certain world, and can attach it to them" (Heidi, Consumer).

Reflecting on her experiences both as a museum curator and a vintage consumer, Heidi acknowledges how her knowledge and imagination of the past changes her perception of old items and the meaning assigned to them (Pearce, 1993). Through consumption she is able to imagine her possession's previous life and conjure up various meanings and associations that 
are infused with historical understandings. Heidi's reflections shared similarities with how other participants interact with their vintage possessions, whereby a seemingly ordinary item is seen as potentially conveying a 'hidden' historical or meaningful association (Appelgren \& Bohlin, 2015). In order to connect "the object and the story", participants may utilize deductions (from looking at or researching an object) alongside their historical knowledge or imagination to construct a narrative. It is clear that imagined pasts play key roles in the fascination for objects, as depicted by Emily and Jamie:

"I don't know how old they are [glass bottles], and it would actually be my next step to research the companies [that produced them] and work that out. [I] like imagining them being on a shelf in this old kind of pharmacy with a man with a big Victorian moustache...behind the counter, and that's kind of cool. Then at some point [they] will have been sat in someone's bathroom, or kitchen....and then it continues its journey from there. So, thinking about all the people that would have owned this item or had it near them and then...how on earth did it end up....in Old Trafford? It's pretty interesting" (Emily, Consumer).

"I don't know really why I like it [an Indo-Persian war shield at his home]. I think...you can imagine its history, obviously, it's had a life. At some point it's been held by somebody with... a sword...possibly in a battle. It's seen some action and...it carries that...I don't know whether it has or not, it may have had...only ever been ornamental, I don't know, but, in my imagination, it's had that life. Then you've got to wonder how it's got from Indo-Persia to the charity shop in Oldham? [...]. What's been its journey? [...] all these things go through your head when you see an object like that. So...yeah, it's got an imagined history” (Jamie, Trader).

Participants are fully aware that their possessions have had a previous life, yet their level of understanding varies and sometimes involves speculation rather than known facts (Appelgren \& Bohlin, 2015). For example, both Emily and Jamie speculate about their objects' actual or imagined previous owners and other possible historical associations. This speculation about the object's former life and its journey to the present is often shaped by individuals' own 
perceptions of the past and their fantasies and imaginations (Appelgren \& Bohlin, 2015; Mullins, 2018). This interpretation process might involve overlooking possible details about the object's past (e.g. "ornamental object") to give space to preferred interpretations (e.g. used "in a battle"). Similarly, Emily later reflects on her constructed interpretation: "probably not [Victorian] really, I'm probably exaggerating that [laughs], but it's the romantic vision in the mind". In that sense, these consumers of old objects demonstrate an awareness of their use of elements of imagination while continuing to indulge in this kind of meaning-making.

Individuals' romantic outlooks of the past, therefore, construct a partially fictitious world concerning the items' existence prior to their encounters with old objects. An item detached from its original temporal and socio-cultural context often acquires new meanings. Given consumers' detachment from the original context, they attempt to fill the gaps, often by projecting their perceptions of the past which is, of course, influenced by contemporary circumstances (Mead, 1959; Pearce, 1993). Both traders and consumers go through a similar interpretation process, whereby gaps in knowledge about the object's past are completed through their imaginations. Such assigned meanings and associations have the potential to initiate not only consumption, but also acts of curation to which we now turn.

\subsection{Curatorial practices}

Perceiving old objects as meaningful, vintage enthusiasts often engage in curatorial practices to ensure objects' preservation. This is evident in participants' interpretations of their consumption as a form of guardianship of the past:

"Some of us are the collectors and curators of things that need to be valued not necessarily in monetary terms [...]. Maybe kind of guardians of culture and history" (Naomi, Consumer).

"I like to rescue them and preserve them because otherwise I think they're just going to get lost forever and no one's going to really be bothered about them" (Clare, Consumer). 
Both Naomi and Clare position their vintage consumption as preserving facets from the past which they value. Naomi highlights that while some old items might not be valued from a monetary perspective, they could be valued due to their cultural and historical associations (Pearce, 1993). Similarly, Clare safeguards objects such as old photographs that are linked with socio-cultural rituals such as weddings. She positions herself as rescuing these artefacts in order to provide social recognition of their value, in this case paying respect to the married couples in the photographs:

"Also, I guess preserve the memory of the people who got married because quite often I think the couple in the photo [...] are all dead now. So quite often you'll get house clearances and family don't want the photos [...] and then they just end up in random places all ripped up and it's just a bit horrible really. I like to collect them and look after them" (Clare, Consumer).

House clearances allow families to dispose of unwanted possessions of a deceased relative and provide one of the means by which vintage traders obtain their merchandise. However, Clare disapproves of families' disposal of such personal possessions. She views this as transforming a sacred and complete wedding album into a set of profane, scattered and perhaps neglected commodities in the marketplace (Belk et al., 1989). She also specifically critiqued the practice of purposefully dividing a photo album and selling pictures separately: “... a bit of a desecration really to pull them apart". This practice also disrupts previous owners' curatorial efforts, as pictures might be "lost forever". Clare attempts to prevent this "desecration" through her curatorial practices, as she states:

"So quite often on eBay if there's ones that are separated out or sold separately from the same wedding I'll buy as many as I can find from the same wedding and try [to] keep them together. Because otherwise it's just sad isn't it?" (Clare, Consumer).

Objects' associations with the past provoke Clare's actions; she attempts to restore the sacredness of a wedding album, through the ritual of purchasing and reuniting scattered images 
(Belk \& Humayun, 2015; Belk et al., 1989). Clare's curatorial role brings her experiences closer to a museum curator, who preserves and cares for old items on the behalf of others.

\subsection{Future imaginations and transference}

The perception that possessions are valuable or meaningful encourages participants to preserve them and initiate their transferal to new owners. Two strategies of object transference are identified: selling and gift-giving, whereby objects are passed to others who would ensure their preservation. Through the sale of objects to other enthusiasts, participants note how a vintage object is continuously circulated in the marketplace:

"My wardrobe at home is virtually a vintage shop, collections of overcoats and jackets and suits [...] when a vintage trader finds something that fits them perfectly in clothing, for instance, you would be very loathed to sell it on [...]. Having said that, some of the items that you cosset and wear with pride month after month after month eventually you get to a point where you think, I am a bit tired of this now [...]. So, there's another angle on vintage goods...you own things, you enjoy them, you use them and then sell them on and let somebody else do the same" (Alex, Trader).

"The one good thing about vintage as opposed to modern retail is it does tend to hold its value; so, you've spent 50 or $£ 60$ on a hat or a bag, well, the likelihood is you can sell it on for 50 or $£ 60$, because it's already got 80 years history [...]. We do what's called a release-it-to-the-wild programme in the vintage circuit, which basically means 'oh, I'm sorry [...] I've been keeping it in my wardrobe or closet and it's not being used, I'm going to release it to the wild, come on girlfriends, knock yourselves out',' (Carole, Consumer).

Both Carole and Alex suggest that person-object relationships are fluid, with some oncecherished items ultimately becoming unused and less special (Masset \& Decrop, 2016). This also illustrates how consumption roles in the vintage marketplace can be fluid: traders sometimes purchase items for their personal use, whereas customers may transform into traders selling their possessions to others. Through the sale of possessions to other vintage enthusiasts, 
individuals ensure the preservation of old objects, which become part of a circulation loop, continuously moving from one home to another, across time and place. This process informs the accumulation of additional historical layers and meanings (Appelgren \& Bohlin, 2015; Pearce, 1993). The associated knowledge and imagination of objects' past play a role in shaping the meanings assigned to them, and in influencing how consumers interact with their possessions, as illustrated below:

"They've belonged to other people and they've been important to other people, and I think that's really important to acknowledge. Most of the time, they've been very well-made because things in the past [...] weren't made to be thrown-away...and there's craftsmanship [...]. It's been well-made, it's been well-maintained until you got it, that means it's been loved until the point at which you got it and I think you've got a responsibility to continue loving it in the same way" (Lesley, Consumer).

Lesley reveals a sense of duty to continue the work of those who have come before her in curating items. Moreover, she reveals a respect for elements of the past (e.g. "craftsmanship") and the care taken in old objects' preservation, which she contrasts with a contemporary throwaway culture that puts the longevity of objects at risk (Cherrier, 2010). In contrast to studies that perceive curatorial consumption to involve merely continuing the work of ancestors in preserving the family past (McCracken, 1988a; Curasi et al., 2004), participants like Lesley, feel responsible to continue the work of the stranger(s) who preceded them in "loving" and curating old objects they purchased from the marketplace. Accordingly, vintage enthusiasts may envisage that their ownership of an object is merely a temporary episode in the object's long biography. This elicits a sense obligation towards the old object (i.e. " $a$ responsibility to continue loving it in the same way"); the recognition of the objects' histories have the potential to initiate curation.

Another form of object transference involves gift-giving. While previous research identifies the transferal of heirlooms amongst family members (Curasi et al., 2004), some 
participants noted a preference for donating possessions to museums, due to their historical significance. After acquiring a box lot from an auction, Dominic states:

"I found a pile of negatives showing displaced people and refugees from World War II boarding an American ship to start a new life in America [....]. The name of the ship turns up in some of the pictures. So, I was able to look at the history of the ship and found that it was one of two ships that were especially assigned by President Truman to pick up refugees from Europe [...]. I contacted the holocaust museum in New York, and they said 'yeah, we most definitely would like copies of those scans'," (Dominic, Trader).

Dominic's examination of the negatives, coupled with further research, allows him to develop a better understanding of their past and insights about the ship "USS Ernie Pyle", tracing the images to “Antwerp in 1947'. However, he sees his responsibility as going beyond the preservation of the images, to ensure that they reach a larger audience in a museum setting. Moreover, Dominic suggests that given the images "are so sharp you might even recognize certain individuals" they could assist people "looking for an image of their granddad leaving Antwerp". Hence, their public display enables attempts to trace family histories, and the potential to reconnect with ancestors through the images. In this sense, Dominic's curatorial role is not limited to preserving old items but is sensitive to individual histories and families' pasts. However, in retaining the originals, Dominic successfully navigates between two conflicting forms of value; he attains moral value from helping others, yet his continued possession of the originals allows the potential for a future income.

This form of gift-giving was also present in the consumer narratives. Here, Heidi also suggests that museums can benefit from transference processes:

"I would say most museums now don't have a budget really, to purchase anything, so they rely entirely on donations [...]. Somebody will be a collector [...] and then as they've got older, their kids won't want it [...]. I think people take quite a lot of pride, or they feel comfortable with it going into the hands of a public collection. Firstly, I think, because they get a bit of 
recognition out of that, and also it kind of goes down in history, rather than just going into some bin somewhere" (Heidi, Consumer).

Heidi's experiences reveal an unconsidered aspect related to the disposal of cherished and family possessions (Price et al, 2000; Curasi et al., 2004). While previous research notes that consumers who are unable to find an interested recipient within their families might turn to the marketplace (Lastovicka \& Fernandez, 2005; Price et al., 2000), consumers may also turn to cultural institutions. By donating objects to museums, consumers acknowledge their historical significance whilst ensuring their preservation, essentially maintaining or increasing the object's sacredness by its inclusion in a museum collection (Belk et al., 1989). The "recognition" that comes with the donation potentially affords consumers symbolic immortality as they become forever associated with the collection (Belk, 1995; Price et al., 2000). Also, Heidi states: "if they [the donors] pass it on to a museum, they'll also give us the story." This transferal of assigned memories, meanings and details about the previous owner(s) echoes the transferal of heirlooms within a family (Price et al, 2000; Curasi et al., 2004). Accordingly, those consumers could be seen as using museums as mediums to display and communicate the history and meaning of items regarded as significant for future generations.

However, museums may also dispose of items that are in their possession, a notion Heidi hints at saying "it's sort of like preserved forever, or as long as we can keep it". Museums could dispose of items through their sale (Pearce, 1993), providing a source for new stock, with the added benefit of associated stories and 'known' histories. For example, Lisa, a trader, mentioned having an item which belonged to a museum: "I bought it from a Czech dealer who was cleaning out a university museum". This enables her to tell potential consumers about the item's past life, as she states, "it's kind of helps them understand the object". An item's past life as a museum piece might increase its significance in the eyes of consumers (Kopytoff, 
1986; Belk et al., 1989), with such associations initiating consumers' desires to ensure objects' preservation, thus potentially restarting the curatorial cycle (Figure.1).

\section{Discussion}

In this paper, we explore how old objects' circulation impacts the meanings assigned to possessions and individuals' interactions with them. Our findings enable us to develop a conceptualization of curatorial consumption consisting of four components: object histories, curatorial practices, future imaginations and transference (Figure.1). This allows us to contribute to existing understandings of consumers' relationships with their possessions, by offering a wider view of curation which highlights how facets of the past are preserved in contemporary consumer culture. We highlight the circular nature of curation, as historical objects are continuously exchanged, and therefore, preserved by those who value them. In doing so, we illustrate the collaborative essence of curation, as objects of the past are acquired, interpreted and preserved (by individuals and sometimes institutions), throughout the objects' biographies.

We contribute to the materiality literature, by identifying how objects' circulation across different temporal-spatial contexts elicits consumers' imaginations and actions (Appelgren \& Bohlin, 2015; Pearce, 1993). A material culture lens enables us to highlight that old curated objects are not inert, as is suggested by prior research (Curasi et al., 2004; McCracken, 1988a). Rather, old objects' longevity allows them to play an active role in shaping the manner consumers interact with them (Miller, 2010; Pearce, 1993). We illustrate how consumers' recognition of their possessions' previous 'lives' and actual or imagined associations with people, places and eras helps to shape the meanings they assign to them (Grayson \& Martinec, 2004; Pearce, 1993). In doing so, we highlight the interplay between consumers' perceptions of the past and objects' historical associations in facilitating consumption and also acts of curation. 
Our focus on vintage markets enables us to respond to a recent call for research that examines the "interplay of multi-temporal forces embedded [into objects], beyond family history" (Türe \& Ger, 2016, p.21). We identify how old objects' circulation enables consumers to navigate imagined temporalities (i.e. perceptions of past, present and future) impacting their relationships with possessions. In contrast to prior work that perceives old curated objects as fixed 'archives' of the past (Curasi et al., 2004; McCracken, 1988a), we note that constant circulation extends objects' biographies, inscribing them with additional historical layers, allowing consumers to develop new meanings and associations (Appelgren \& Bohlin, 2015; Pearce, 1993). We also note the impact of consumers' nostalgia for a vicarious past in shaping not only vintage consumption (Duffy et al., 2012; Goulding, 2002), but also the meanings of curated items.

We propose that our conceptualization of curatorial consumption offers potential theoretical insights beyond the vintage marketplace, with the potential to encompass other consumption contexts where individuals interact with facets of the past. For example, our more nuanced understanding is relevant to prior research findings such as the practices identified by Kuruoğlu and Ger (2015) including recording, listening, hiding and circulating music cassettes. These actions could be understood as reflecting curatorial practices whereby the meanings embodied within the recordings are preserved through the circulation of cassettes and the common heritage experienced by community members.

Our curatorial focus contributes to existing understandings of ownership. Previous research suggests that when buying second-hand items from strangers "the perceived contagion of prior owners is something we seek to erase" (Belk, 2014, p.34), as we appropriate and make them our possessions (Kopytoff, 1986). Conversely, for items owned by ancestors or admired individuals, the traces of previous owners can positively contaminate objects, informing their sacred nature (Belk et al., 1989; Curasi et al., 2004). However, we note that for some 
consumers, it is not only objects' known past, but also their presumed historic associations which contribute to their fascination with second-hand possessions. Instead of fully erasing their old objects' histories, including links to previous owners, our participants seek to add historical layers in their objects' biographies.

Consumers' understanding of the length of their old object's lifespan often shapes not just their perceptions and actions towards them (Miller, 2010; Pearce, 1993), but also highlights the temporary nature of their ownership. Engaging in curatorial consumption informs a different understanding of possessions, wherein consumers understand their ownership of historical objects as just an episode in these objects' longer biographies. Consumers' perceptions of their objects' histories elicit a sense of responsibility to ensure that objects are preserved, serving to legitimize their transference to others, who might continue their curatorial efforts (Price et al., 2000). Curatorial consumption, therefore, highlights that ownership of old objects is neither stable nor enduring, as objects continue their journeys into the future through transference, from one owner to another across time and place and continuing the consumption cycle.

Our findings have implications for literature concerning consumers' collections, yet it is worth acknowledging that not all our participants were collectors; Belk (2014, p.34) points out "unless [consumers] continue to add to the collection, [they] are curating without collecting". In addition, while prior research has noted consumers' tendency to "justify a collection falsely in terms of its contribution to art, science or history" (Belk, 1995, p.125), it is clear that consumers recognized the value of museums as collective memories. Donating to museums allowed individuals to feel they are transferring their old objects responsibly and extending themselves through their donations (Belk, 1995).

According to Graeber (2001, p.254), "value is the way actions become meaningful to the actors by being placed in some larger social whole, real or imaginary". Our findings speak to 
this notion, and understandings of value emerging from consumers' actions, as well as objects' circulation (Arsel, 2016; Figueiredo \& Scaraboto, 2016; Gollnhofer, Weijo, \& Schouten, 2019; Türe, 2014). We note that consumers may attain different forms of value from engaging in curatorial consumption. For example, consumers can attain moral value when they preserve objects (e.g. donating to museums), whereas selling curated items indicates monetary value (Türe, 2014). Objects' circulation across temporal-spatial contexts may enable consumers to imagine themselves as part of a curatorial chain, consisting of those who preceded them in owning, cherishing, and maintaining items. Hence, objects' circulation enables consumers to attain linking value with others, allowing the construction of a collective identity (Curasi et al., 2004; Figueiredo \& Scaraboto, 2016). Moreover, objects' past associations alongside individuals' actions (e.g. curatorial practices), allows the maintenance or the creation of an object's symbolic or monetary value (Parsons, 2008; Pearce, 1993).

In highlighting the significance of old objects' pasts in shaping the meanings assigned to them in the marketplace, our study has managerial implications. First, with the increasing popularity of consuming old objects (McColl et al., 2013; Mintel, 2019), marketers can utilize their merchandise histories as a marketing tool, leveraging their products' and brands' past by sharing products' biographies. While the role of past associations in storytelling has been recognized in the context of retro brands (Brown et al., 2003), and upcycled products (Kamleitner et al., 2019), we suggest its potential with second-hand possessions. Researching and sharing (plausible) object histories, and accurate information about associated historical eras, helps to shape perceptions of authenticity (Grayson \& Martinec, 2004). In this way sellers elicit consumers' imaginations, allowing them to conjure up their own meanings and associations around a product, encouraging them to contribute to the object's continuing biography. Second, as high street retailers and brands (e.g. Urban Outfitters' vintage offering, Urban Renewal) begin to more fully embrace the second-hand market (Mintel, 2019), we 
suggest that marketers can build on our findings, purposefully embedding their products with elements of the past. There is also the potential for marketers to further develop the potential of gifting old objects beyond the heirloom context, emphasizing the uniqueness of second-hand goods and engaging with consumers' desires for sentimental gifts (Givi \& Galak, 2017).

\section{Conclusion}

This paper contributes to current understandings of consumer-object relations, by developing a conceptualization of curatorial consumption to shed light on how valued remnants of the past are acquired, circulated and preserved in contemporary consumer culture. We perceive curatorial consumption as a wider process incorporating practices such as the acquisition, interpretation, preservation, use and/or display of items, as well as the transference of objects amongst those who value them. We also highlight the role of objects' circulation and actual or imagined histories in shaping consumption practices and the meanings of old objects (Appelgren \& Bohlin, 2015; Pearce, 1993). Moreover, this study indicates the usefulness of putting consumers' material possessions at the center of interviews. As we have illustrated, objects can serve as a useful medium to provoke interviewees' narratives and to develop an indepth understanding of their relationships with their possessions and their consumption practices. Therefore, we suggest object-centered interviews potentially facilitate richer insights into consumers' relationships with their possessions and with others (Woodward, 2019).

However, given our exploratory focus we acknowledge certain limitations, which inform our suggestions for future studies, namely the specific focus of our context. Our focus on the vintage marketplace could be usefully extended to other contexts in order to further develop the value of the curatorial lens in exploring consumers' relationships with historic objects and institutions. Moreover, given that consumption is heavily influenced by cultural perspectives (Jafari et al., 2012), we call for future studies to investigate the interplay of perceptions of the 
past and historic objects in non-western contexts in order to fully develop our understanding of the curatorial process and consumers' relationships with old possessions. 


\section{References}

Abdelrahman, O. K., Banister, E., \& Hampson, D. (2019). "I'm only a Guardian of these

Objects": Vintage traders, Curatorial consumption and the meaning(s) of objects.

Research in Consumer Behavior, 20, 55-69.

Appadurai, A. (1986). The social life of things: Commodities in cultural perspective.

Cambridge: Cambridge University Press.

Appelgren, S., \& Bohlin, A. (2015). Growing in Motion: The Circulation of Used Things on Second-hand Markets. Culture Unbound: Journal of Current Cultural Research, 7(1), $143-168$.

Aronczyk, M., \& Craig, A. (2012). Introduction: Cultures of circulation. Poetics, 40(2), 93100.

Arsel, Z. (2016). Assembling markets and value. In R. Canniford \& D. Bajde (Eds.), Assembling consumption: Researching actors, networks and markets (pp. 32-41). New York: Routledge.

Bardhi, F., \& Eckhardt, G. M. (2017). Liquid consumption. Journal of Consumer Research, 44(3), 582-597.

Belk, R. W. (1995). Collecting in a Consumer Society. London: Routledge.

Belk, R. W. (2014). Ownership and collecting. In The Oxford handbook of hoarding and acquiring (pp. 32-42). Oxford: Oxford University Press.

Belk, R. W., Fischer, E., \& Kozinets, R. V. (2013). Qualitative Consumer and Marketing Research. London: Sage.

Belk, R. W., \& Humayun, M. (2015). Object Agency and the Extended Object. Asia-Pacific Advances in Consumer Research, 11, 21-23.

Belk, R. W., Wallendorf, M., \& Sherry, J. F. (1989). The sacred and the profane in consumer behavior: Theodicy on the odyssey. Journal of Consumer Research, 16(1), 1-38. 
Bettany, S. M., Kerrane, B., \& Hogg, M. K. (2014). The material-semiotics of fatherhood: The co-emergence of technology and contemporary fatherhood. Journal of Business Research, 67(7), 1544-1551.

Bramley, E. V. (2019). Is buying vintage clothing the most eco way to shop? The Guardian. Retrieved from https://www.theguardian.com/fashion/2019/apr/25/the-vintagecomeback-is-it-the-solution-to-sustainable-shopping

Brown, S., Kozinets, R. V., \& Sherry, J. F. (2003). Teaching old brands new tricks: Retro branding and the revival of brand meaning. Journal of Marketing, 67(3), 19-33.

Cherrier, H. (2010). Custodian behavior: A material expression of anti-consumerism. Consumption Markets \& Culture, 13(3), 259-272.

Chronis, A., Arnould, E. J., \& Hampton, R. D. (2012). Gettysburg re-imagined: The role of narrative imagination in consumption experience. Consumption Markets and Culture, 15(3), 261-286.

Curasi, C. F., Price, L. L., \& Arnould, E. J. (2004). How Individuals' Cherished Possessions Become Families' Inalienable Wealth. Journal of Consumer Research, 31(3), 609-622.

Duffy, K., Hewer, P., \& Wilson, J. (2012). Granny would be proud: On the labours of doing vintage, practices and emergent socialities. Advances in Consumer Research, 40, 519525.

Epp, A. M., \& Price, L. L. (2010). The Storied Life of Singularized Objects: Forces of Agency and Network Transformation. Journal of Consumer Research, 36(5), 820-837.

Ferreira, M. C., \& Scaraboto, D. (2016). "My plastic dreams": Towards an extended understanding of materiality and the shaping of consumer identities. Journal of Business Research, 69(1), 191-207.

Figueiredo, B., \& Scaraboto, D. (2016). The systemic creation of value through circulation in collaborative consumer networks. Journal of Consumer Research, 43(4), 509-533. 
Givi, J., \& Galak, J. (2017). Sentimental value and gift giving: Givers' fears of getting it wrong prevents them from getting it right. Journal of Consumer Psychology, 27(4), $473-479$.

Gollnhofer, J. F., Weijo, H. A., \& Schouten, J. W. (2019). Consumer movements and value regimes: Fighting food waste in Germany by building alternative object pathways. Journal of Consumer Research, 46(3), 460-482.

Goulding, C. (2002). An Exploratory Study of Age Related Vicarious Nostalgia and Aesthetic Consumption. Advances in Consumer Research, 29(1), 542-547.

Graeber, D. (2001). Toward an Anthropological Theory of Value: The false coin of our own dreams. New York: Palgrave.

Grayson, K., \& Martinec, R. (2004). Consumer Perceptions of Iconicity and Indexicality and Their Influence on Assessments of Authentic Market Offerings. Journal of Consumer Research, 31(2), 296-312.

Jafari, A., Firat, F., Suerdem, A., Askegaard, S., \& Dalli, D. (2012). Non-western contexts: The invisible half. Marketing Theory, 12(1), 3-12.

Kamleitner, B., Thürridl, C., \& Martin, B. A. S. (2019). A Cinderella Story: How Past Identity Salience Boosts Demand for Repurposed Products. Journal of Marketing, 83(6), 76-92.

Kopytoff, I. (1986). The cultural biography of things: commoditization as process. In A. Appadurai (Ed.), The social life of things: Commodities in cultural perspective (pp. 6491). Cambridge: Cambridge University Press.

Kuruoğlu, A. P., \& Ger, G. (2015). An emotional economy of mundane objects. Consumption Markets and Culture, 18(3), 209-238.

Lastovicka, J. L., \& Fernandez, K. V. (2005). Three Paths to Disposition: The Movement of Meaningful Possessions to Strangers. Journal of Consumer Research, 31(4), 813-823. 
Masset, J., \& Decrop, A. (2016). “God, I have so many ashtrays!” Dependences and dependencies in consumer-possession relationships. Journal of Business Research, 69(1), 94-109.

McColl, J., Canning, C., McBride, L., Nobbs, K., \& Shearer, L. (2013). It's Vintage Darling! An exploration of vintage fashion retailing. Journal of the Textile Institute, 104(2), 140150.

McCracken, G. (1988a). Culture and Consumption. Bloomington: Indiana University Press.

McCracken, G. (1988b). The long Interview. London: Sage.

Mead, G. H. (1959). The Philosophy of The Present. La Salle,IL: Open Court.

Miller, D. (2010). Stuff. Cambridge: Polity.

Mintel. (2019). The rise of second-hand fashion. Mintel Report.

Mullins, P. R. (2018). The Materiality of Consumer Culture. In O. Kravets, P. Maclaran, S. Miles, \& A. Venkatesh (Eds.), The SAGE Handbook of Consumer Culture (pp. 351364). London: Sage.

Parsons, E. (2008). Thompsons' rubbish theory: exploring the practices of value creation. Advances in Consumer Research, 8, 390-393.

Pearce, S. M. (1993). Museums, Objects and Collections: A Cultural Study. Washington,DC: Smithsonian Books.

Price, L. L., Arnould, E. J., \& Curasi, C. F. (2000). Older Consumers' Disposition of Special Possessions. Journal of Consumer Research, 27(2), 179-201.

Spiggle, S. (1994). Analysis and Interpretation of Qualitative Data in Consumer Research. Journal of Consumer Research, 21(3), 491.

Thompson, C. J. (1997). Interpreting Consumers: A Hermeneutical Framework for Deriving Marketing Insights from the Texts of Consumers' Consumption Stories. Journal of Marketing Research, 34(4), 438-455. 
Türe, M. (2014). Value-in-disposition. Marketing Theory, 14(1), 53-72.

Türe, M., \& Ger, G. (2016). Continuity through Change: Navigating Temporalities through Heirloom Rejuvenation. Journal of Consumer Research, 43(1), 1-25.

Turunen, L. L. M., \& Leipämaa-Leskinen, H. (2015). Pre-loved luxury: Identifying the meanings of second-hand luxury possessions. Journal of Product \& Brand Management, 24(1), 57-65.

Woodward, S. (2019). Material Methods: Researching and Thinking with Things. London: Sage. 
Table 1: Participant profiles

\begin{tabular}{|c|c|c|c|}
\hline Pseudonym & Gender & Age & Occupation \\
\hline Dominic & Male & 58 & Trader \\
\hline Mary & Female & 51 & Trader \\
\hline Alex & Male & 61 & Trader \\
\hline Susan & Female & 51 & Trader \\
\hline Joan & Female & 63 & Trader \\
\hline Dinah & Female & 59 & Trader \\
\hline Jade & Female & 47 & Trader \\
\hline John & Male & 60 & Trader \\
\hline Jamie & Male & 57 & Trader \\
\hline Kathy & Female & 69 & Trader \\
\hline Lisa & Female & 49 & Trader \\
\hline Peter & Male & 51 & Trader \\
\hline Mark & Male & 80 & Trader \\
\hline Natalie & Female & 50 & Trader \\
\hline Tracey & Female & 63 & Trader \\
\hline Brandon & Male & 29 & Self-employed \\
\hline Chris & Female & 52 & Nurse \\
\hline Stan & Male & 62 & Retired \\
\hline Margret & Female & 56 & Retired \\
\hline Nora & Female & 41 & Fundraising Manager \\
\hline Mayra & Female & 34 & PhD student \\
\hline Andrew & Male & 57 & Academic \\
\hline Lesley & Female & 36 & College administrator \\
\hline Carole & Female & 45 & Dress maker \\
\hline Clare & Female & 30 & Researcher \\
\hline Heidi & Female & 28 & Museum curator \\
\hline Emily & Female & 28 & Specialist-Nurse \\
\hline Naomi & Female & 59 & \\
\hline & & & 59 \\
\hline
\end{tabular}


Figure.1. Conceptualizing Curatorial Consumption

Circulation of meanings and stories during object transfer

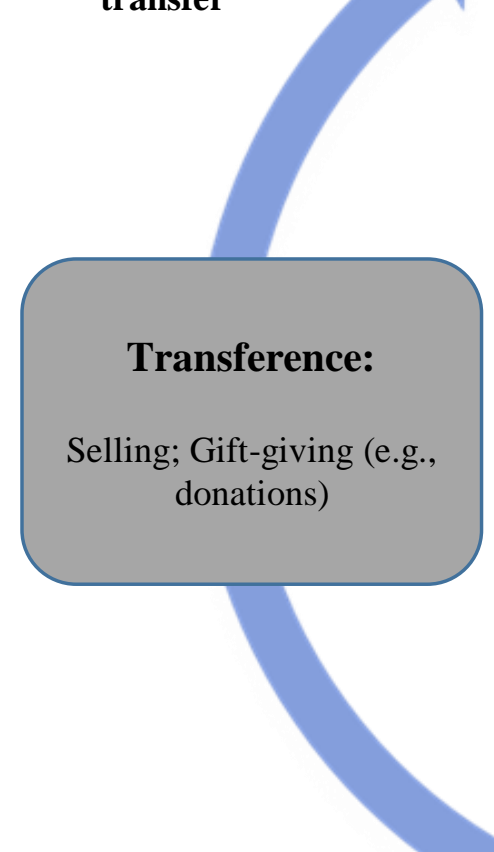

Reflecting on the present, imagining the past/future; projecting those reflections onto object

\section{Object histories:}

Perceptions of the past; object's actual/imagined associations with people, places, eras

\section{Future} imaginations:

Fate of possessions incorporating a person's perceptions of the past/future
Curatorial practices:

Acquisition;

Interpretation;

Preservation;

Usage/display of object object 